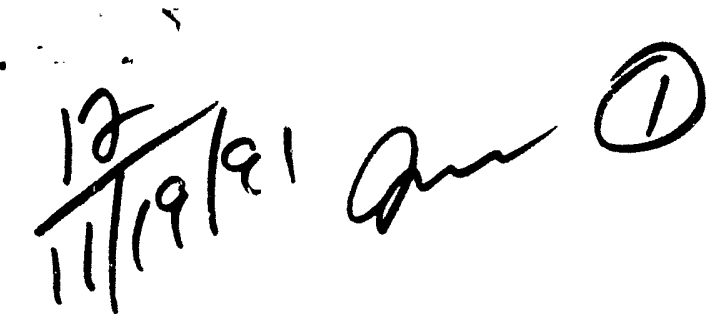

UCRL-ID- -108601

DE 92003049

\title{
Capabilities Required to Conduct the LLNL Plutonium Mission
}

\author{
J. Kass, W. Bish, A. Copeland, J. West, S. Sack, and B. Myers
}

September 10, 1991

This is an informal report intended primarily for internal or limited external distribution. The opinions and conclusions stated are those of the author and may or may nor be those of the Laboratory:

Nork performed under the auspices of the L.S. Department of Energy by the iawrence Livermore National Laboratory under Contract W-7405-Eng-48. 


\section{DISCLAIMER}

This document was prepared as an acccount of work sponsored by an agency of the United States Government. Neither the United States Government nor the University of California nor any of their employees, makes any warranty, express or implied, or assumes any legal liability or responsibility for the accuracy, completeness, or usefulness of any information, apparatus, product, or process disclosed, or represents that its use would not infringe privately own rights. Reference herein to any specific commercial products, process, or service by trade name, trademark, manufacturer, or otherwise, does not necessarily constitute or imply its endorsement, recommendation, or favoring by the United States Government or the University of California. The views and opinions of authors expressed herein do not necessarily state or reflect those of the United States Government or the University of California, and shall not be used for advertising or product endorsement purposes.

This report has been reproduced directly from the best available copy.

Available to DOE and DOE contractors from the Office of Scientific and Technical Information P.O. Box 62, Oak Ridge, TN 37831

Prices available from (615) 576-8401, FTS 626-8401

Available to the public from the

National Technical Information Service

U.S. Department of Commerce

5285 Port Royal Rd.

Springfield, VA 22161 


\title{
Capabilities Required to Conduct The
}

LLNL Plutonium Mission

\author{
prepared by \\ J. Kass, W. Bish, A. Copeland, J. West, S. Sáck, and B. Myers
}

September 10, 1991 


\title{
Capabilities Required to Conduct The \\ LLNL Plutonium Mission
}

prepared by

\author{
J. Kass, W. Bish, A. Copeland, J. West, S. Sack, and B. Myers \\ Executive Summary:
}

This report outlines the LLNL plutonium related mission anticipated over the next decade and defines the capabilities required to meet that mission wherever the Plutonium Facility is located.

If plutonium work is relocated to a place where the facility is shared, then some capabilities can be commonly used by the sharing parties. However, it is essential that LLNL independently control about $20000 \mathrm{sq} \mathrm{ft}$ of net lab space, filled with LLNL controlled equipment, and staffed by LLNL employees.

It is estimated that the cost to construct this facility should range from $\$ 140 \mathrm{M}$ to $\$ 200 \mathrm{M}$. Purchase and installation of equipment to replace that already in Bldg 332, along with additional equipment identified as being needed to meet the mission for the next ten to fifteen years, is estimated to cost $\$ 118 \mathrm{M}$. About $\$ 29 \mathrm{M}$ of the equipment could be shared.

The Hardened Engineering Test Building (HETB) with its additional 8000 sq $\mathrm{ft}$ of unique test capability must also be replaced. The fully equipped replacement cost is estimated to be about $\$ 10 \mathrm{M}$.

About $40000 \mathrm{sq} \mathrm{ft}$ of setup and support space are needed along with office and related facilities for a 130 person resident staff. The setup space is estimated to cost $\$ 8 \mathrm{M}$. The annual cost of a 130 person resident staff (100 programmatic and 30 facility operation) is estimated to be $\$ 20 \mathrm{M}$.

\section{A. Conclusions:}

Research and Development capability on plutonium, its alloys and compounds remains a critical component of the Defense Systems Program. There is a continuing need to support weapons design and evaluation. The increased emphasis on weapons safety, as outlined in the Drell Committee Report as well as the need to develop more efficient production and fabrication techniques at Rocky Flats Plant (RFP) or its replacement demand the support of a strong and innovative plutonium program.

Building 332, the existing facility, contains abcut $24500 \mathrm{sq} \mathrm{ft}$ net usable Category I lab space. Increment I contains $18000 \mathrm{sq} f t$ and Increment 3 contains $6500 \mathrm{sq} \mathrm{ft}$. The Weapons Program utilizes the test device component fabrication, enhanced safety, manufacturing, and weaponization space. The Advanced Plutonium 
Technology (APT) Program utilizes the pyrochemical and related plutonium processing space. The APT program is in need of additional space to accommodate the expansion of activities planned to occur within the Plutonium facility. The analytical chemistry, metallography, vault, and waste processing space is shared by all the programs. The Hardened Engineering Test Building (HETB) provides a unique set of test capabilities for assemblies containing plutori:um. The $8000 \mathrm{sq} \mathrm{ft}$ engineering test area is fully instrumented and contains an electrodynamic shaker, a thermal chamber, and a vertical impact machine. Its operation is impractical without access to a vault. The Weapons and APT programs utilize extensive setup and staging space outside the Category I facility with some of that space located within the Superblock.

Current activities support physics design, enhanced safety, stockpile maintenance and surveillance, as weil as manufacturing and process development for reconfiguration to Complex 21.

If the plutonium facility is relocated to another location where the facility is shared, then the capabilities must include those used in common by the sharing parties and those used exclusively by LLNL. Increased cost effectiveness can be achieved if the service functions are shared. However, it is absolutely essential that LLNL have its own capabilities for weaponization, enhanced safety, metallurgy, as well as manufacturing and process development. This must consist of space and equipment dedicated to LLNL programmatic requirements, and staffed by LLNL employees. Meeting this requirement is essential to retain the independent ability of LLNL to contribute to the mission. It is clear that we need about $20000 \mathrm{sq} \mathrm{ft}$ of Category I net lab space independently controlled by LLNL. We need ready access to specialized pieces of equipment that are difficult to schedule for shared work or are unique prototypes integral to LLNL development programs. Examples include Surry 91, W89 Mod I fire safety, tilt pour development, and CEPOD development. Replacement of the unique and important HETB facility with ready access to a vault is a key to our weaponization program. About $40000 \mathrm{sq} \mathrm{ft}$ of support space with $10000 \mathrm{sq} \mathrm{ft}$ of that near the Category I space is required for effective utilization of the actual Category I space.

The total replacement cost for equipment already installed in Bldg 332 is estimated to be $\$ 64 \mathrm{M}$ with $\$ 37 \mathrm{M}$ of that for the Weapons Program and $\$ 27$ for Advanced Plutonium Technology (APT). It has been estimated that an additional $\$ 10 \mathrm{M}$ is needed to conduct the Weapons program mission over the next ten to fifteen years while an additional $\$ 44 \mathrm{M}$ has been estimated as being needed by APT for the same purpose. It is estimated that about $\$ 29 \mathrm{M}$ of the total equipment needed is contained in the device fabrication and characterization areas, which can be shared. How much of this equipment that can be shared is already available at other sites remains to be defined.

Estimates for construction of Category i lab space range from the $\$ 7000$ per net sq $\mathrm{ft}$ for the New Special Recovery Line at Savannah River and the very similar value estimated by Bechtel/LLNL to convert the SIS production facility to a pit production facility, to about $\$ 10000$ per net sq $\mathrm{ft}$ estimated for the Special Nuclear 
Materials Building by LANL. Construction of a nonequipped 20000 net sq $\mathrm{ft}$ building would therefore be estimated to cost between $\$ 140 \mathrm{M}$ to $\$ 200 \mathrm{M}$.

Effective planning is essential to meet the challenges inherent in conducting work of this type remote from LLNL. We must consider the challenges inherent in transfer of staff members, hiring of new staff at the new site, obtaining funding for required equipment, and maintenance of good communications between LLNL and the new site. In a similar relocation conducted within the commercial nuclear power industry, only $10 \%$ of the work force from the home site moved to the new site and it took about four years from completion of construction of the new site to achievement of smooth operations.

\section{B. Background:}

This report outlines the LLNL plutonium related mission anticipated over the next decade and defines the capabilities required to meet that mission wherever the Plutonium Facility is located.

Many studies of the facility and its operations have been conducted since the facility was opened in 1961.In 1987, W. Scanlin (the Principal Deputy Associate Director for Defense Systems) recommended addition of a strong technology leader, increased nuclear test work, and addition of a major research thrust focused on pyrochemical processing. In March 1990, S. Cochran (the Deputy Associate Director for Nuclear Design)/J. Kass (Materials Division Leader) recommended that if we are directed to close the facility, almost all of our work should be done at Rocky Flats Plant (RFP) since it had the strongest existing infrastructure to build on and therefore would probably be less expensive. The study recommended that we pursue the establishment of a national center for plutonium research and development. The study also pointed out the importance, expense, and difficulty in (a) establishing a large (about 60 person) LLNL resident staff and (b) replacement of the Hardened Engineering Test Building (HETB) since its operation without a vault is impractical. It should be noted that the study was focused only on the weapons program and did not include the APT program.

Following the interruption in RFP operations, a presentation was made to C. MacDonald (Associate Director at Large), C. Gatrousis (Associate Director for Chemistry and Materials Science), R. Clough (Deputy Associate Director for Weaponization), and A. Copeland (Nuclear Explosives Engineering Division Leader) in which J. Kass addressed major facility problems, recommended removal of old gloveboxes and installation of new equipment to meet the mission over the next ten years. A draft line item to accomplish this was prepared and submitted to W. Scanlin in June 1991. It emphasized acquisition of advanced equipment for plutonium manufacturing, enhanced safety, weaponization and rnetallurgy. 


\section{LLNL Plutonium Mission:}

While the metallurgy and processing technology of plutonium have been studied for many years, it remains necessary to address items which arise from initiatives and issues such as reconfiguration of the production complex, aging of the stockpile, enhanced safety, and waste minimization. Research and development capability on plutonium, its alloys and compounds, remains therefore, a critical component of the Defense Systems Program. There is a continuing need to support weapons design and evaluation. The increased emphasis on weapons safety, as outlined in the Drell Committee report, and the need to develop more efficient production and fabrication techniques for plutonium components at RFP or a replacement site demand the support of a strong and innovative plutonium program. We must also consider reuse of old pits and to support stockpile improvement programs on existing systems. These goals will require application of new standards; hardware evaluations and revisions may be necessary. Improved materials and designs must be developed to provide increased protection against hypothetical fire or impact events involving nuclear weapons. We must address waste minimization, waste treatment, and reduced worker radiation exposure in development of the fabrication facilities. Innovative ideas as well as facilities to develop and evaluate these ideas are needed.

\section{The Existing Capability in Bldg 332 and Related Facilities:}

Increment $\mathrm{I}$ in Building contains 18000 net usable sq $\mathrm{ft}$ of Category I lab space and Increment 3 contains $6500 \mathrm{sq} \mathrm{ft}$ of the same type of space.

This space is allocated as follows:

NTS test component fab \&

Mfg. Dev. for Reconfiguration 5000

Enhanced Safety

4000

Weaponization

1500

Pyrochem Processing, Dev. for Reconfiguration

3500

EDS (space scheduled for reequipment to support Reconfiguration) $\quad 3000$

Analytical chem \& Metallography $\quad 3500$

Actinide Spectroscopy $\quad 1000$

Vault and Waste Handling $\quad 3000$

Total $\quad 24500$

The Weapons Program utilizes the shot component fabrication, enhanced safety, manufacturing, and weaponization space. The Advanced Plutonium Technology (APT) Program utilizes the pyrochemical and related plutonium processing space. The APT program is in need of additional space to accommodate the expansion of activities planned to occur within the Plutorium facility. The 
Chemistry and Materials Science (C\&MS) Program principally uses the enhanced safety space. The remaining space is shared by all three programs.

HETB provides a unique set of test capabilities for assemblies containing plutonium. The $8000 \mathrm{sq} \mathrm{ft}$ engineering test area is fully instrumented and contains an electrodynamic shaker, a thermal chamber, and a vertical impact machine.

In addition, there are extensive support facilities. The Weapons program utilizes about $10000 \mathrm{sq} \mathrm{ft}$ of setup space outside of the Superblock. This space is used in support of a broad range of activities including enhanced safety; foundry, machining, and inspection; assembly, disassembly, and stockpile support; as well as glovebox design and assembly. The APT Program utilizes $10000 \mathrm{sq} \mathrm{ft}$ of setup space inside Superblock and 21000 sq ft outside Superblock.

A large number of people are employed by the Weapons, APT, and C\&MS programs supported by the plutonium program. There are however, about 100 people who now are very directly working in support of the plutonium program and it is reasonable to expect that this number will increase to about 125 . There about 60 full time programmatic personnel working in the facility and about 35 additional FTE's are utilized to operate the facility.

Current activities ongoing in the facility include the following items:

fabrication for Greenwater and Bristol as well as samples for shock physics experiments, all in support of the nuclear design program; Surry 91, W89 Mod 1 fire safety, as well as research work for molten plutonium and plutonium/uranium containment, all in support of the enhanced safety program; W68 special surveillance, W79 NELA work and W89 Mod 1 station development, all in support of the stockpile program; precision die casting,tilt-pour furnace development, electron beam purification, oxide to metal conversion, molten salt extraction, vacuum finger casting, hydriding/dehydriding, automated gloveboxes, and other advanced technologies, all related to the reconfiguration manufacturing and processing program as well as waste treatment development.

\section{E. Capabilities Needed to Fulfill the Mission:}

Access to the following Category I capabilities is essential to meet the requirements of the mission:

A fully equipped device component fabrication facility including casting, machining, welding, inspection, assembly, and radiography is essential. Design of devices requires preparation of alloys, casting of defect free components, as well as utilization of machining, welding, and assembly techniques to produce components with very closely controlled and characterized dimensions so that physics modeling can be facilitated.

A fully equipped analytical chemistry and metallography facility is required for the device fabrication, plutonium processing, enhanced safety and other 
programs to define the metallurgical and chemical characteristics as well as the metallurgical and chemical reactions of the alloys and components being studied.

A metallurgical studies capability is required to understand and characterize the mechanical behavior of the materials and components being considered for the device fabrication program, the enhanced safety initiatives, and certain aspects of the stockpile program. Advanced metallurgical techniques such as Auger spectroscopy and Transmission Electron Microscopy do not now exist but would be invaluable in understanding the microstructural mechanisms that control properties.

Vault and waste processing capabilities are essential to support the quantities of plutonium utilized as well as to reprocess the scraps. Properly designed facilities are essential for storage, handling, and movement of materials as well as minimization of radiation exposure to workers. Waste processing is an effective waste minimization approach.

Facilities for precision casting including specialized foundry boxes, prototype die casting, assembly, and advanced real time radiography are essential to support the goal of manufacturing plutonium components with reduced radiation exposure and floor space as well as minimizing waste in Complex 21. Real time radiography allows diagnosis of molten metal flow into a die. It is also useful in enhanced safety studies. The prototype production die casting and real time radiography capabilities do not now exist although we are in the process of obtaining the latter.

Extensive facilities for pyrochemical processing as well as waste treatment by both pyrochemical and aqueous means are essential for Complex 21. A number of the plutonium processing technologies developed for the Special Isotope Separation program are directly applicable to the waste processing cycle being developed for Complex 21. Work on many of these technologies will be continued beyond FY91 under Defense Programs and Environmental Restoration/Waste Management funding. Since the processes developed for the SIS program were subject to constraints on material utilization, worker radiation exposure and space requirements far more severe than those for the current RFP operation, they are particularly relevant to Complex 21 .

Extensive facilities for enhanced safety development are required including gloveboxes that allow fire safety testing of full size components in various configurations and the capability to conduct small scale developmental tests of materials, material combinations, and prototypical components. Specialized equipment is required to conduct thermodynamic and kinetic studies required for understanding the operative processes. There is also a need for facilities for compatibility testing. The equipment required includes furnaces and chemical processing crucibles with high quality atmospheric and temperature control, robotically controlled processing hardware, and the capability to work with production sized quantities. 
A Hardened Engineering Test Building is needed to allow environmental testing of live pit assemblies, conduct intrinsic radiation measurements, and support live pit studies. Gloveboxes and work areas suitable for live pit assembly/disassembly are essential.

Facilities are required for assembly and disassembly in support of the weaponization of new systems. This also includes assessments required for weapon control as well as developmer.t of new control techniques.

General purpose gloveboxes, needed that can be readily adapted to specialized purposes, including prototyping of processes for pit reuse and surveillance activities, are required.

Staging areas including some close to the Category I facility are essential for efficient utilization of time and manpower within the facility. It is essential that equipment be assembled and thoroughly checked out prior to initial utilization in the Category I area.

\section{F. Crucial Factors:}

If the LLNL plutoniun capability is moved to another location where the facility is shared, then the capabilities must include those used in common by the sharing parties and those used exclusively by LLNL. Increased cost effectiveness can be achieved if the service functions are shared. These service functions in ' ude analytical chemistry, metallography, vault, and waste handling. It should also be practical to share a very limited amount of non service equipment that is infrequently used. The large furnace used for full sized pit fire safety testing is an example. On the other hand, it is absolutely essential that LLNL have its own capabilities for weaponization, enhanced safety, metallurgy, as well as manufacturing and process development. This must consist of space dedicated to LLNL work that is filled with equipment dedicated to LLNL work, and staffed by LLNL employees. Meeting this requirement is essential to retain the independent ability of LLNL to contribute to the mission. Sharing of these facilities is impractical because they consist of unique prototypes that are integral to LLNL's development program or are specialized pieces of equipment that are difficult to schedule for shared work. The independence of the LLNL program depends on ready access to the unique and specialized equipment as well as the dedicated people.

Based on the information in previous sections, it is clear that we would need about $20000 \mathrm{sq} \mathrm{ft}$ of Category I net lab independently controlled by LLNL. Equipment required for weaponization, enhanced safety, manufacturing and process development, as well as metallurgy is essential. Replacement of the unique and important HETB facility with ready access to a vault is a key to our weaponization program. About $40000 \mathrm{sq} \mathrm{ft}$ of support space with $10000 \mathrm{sq} \mathrm{ft}$ of this near the Cate jory I space is required for effective utilization of the actual Category I space. We should plan on having a resident staff about 100 programmatic personnel with extensive facilities for traveling staff from Livermore.. Advanced and secure 
telecommunications are required for effective transmittal of information. We may also need facility operations staff.

Effective planning is essential to meet the challenges inherent in conducting work of this type remote from LLNL. We must consider the challenges inherent in transfer of staff members, hiring of new staff at the new site, obtaining funding for required equipment, and maintenance of good communications between LLNL and the new site.

There are some lessons that can be learned from a roughly similar experience in private industry. In the late 1960s, General Electric Nuclear Energy Division moved its fuel manufacturing capability from San Jose, California to Wilmington, North Carolina. Dr. Harald Klepfer, then General Manager of the relevant functions related the following observations and lessons learned from that process. Only about $10 \%$ of the San Jose staff transferred to the new location. The staff was built almost from scratch by the management team at the new site. A transition team was formed well in advance that consisted of the key managers of the new site and support staff. Several years were required to affect the planning. The new site construction manager was a key member of the transition team and a mutual commitment was made for him to work at the new site so that he would have to live with the results of the construction. Readily accessible communications were absolutely essential. This included regularly scheduled technical meetings attended by staff and managers up through at least the equivalent of Division Leaders as well as daily communications. Having modern telecommunications would have been "a Godsend". Participation by Finance, Employee Relations, and other services relevant to the employees was essential to solving problems. As is usually the case; attention to detail, contingency planning, and frequent top management briefings to avoid surprises was essential.

\section{G. Detailed Equipment List}

The following is a detailed list of the equipment needed to meet the mission along with an estimate of the replacement costs. The costs are estimated for complete installation. The list includes equipment already available and equipment identified as being needed to meet the mission over the upcoming ten to fifteen years. Equipment not yet available is identified with an asterisk.

The total replacement cost for equipment already installed in Bldg 332 is estimated to be $\$ 64 \mathrm{M}$ with $\$ 37 \mathrm{M}$ of that for the Weapons Program and $\$ 27$ for Advanced Plutonium Technology. Weapons program has estimated that an additional $\$ 10 \mathrm{M}$ is needed to conduct the mission over the next ten to fifteen years while APT has estimated an additional $\$ 44 \mathrm{M}$ for the same purpose. It is estimated that about $\$ 29 \mathrm{M}$ is contained in the Device fabrication and Characterization areas, which can be shared. How much of this equipment that can be shared is already available at other sites remains to be defined. 
Device Fabrication ( $\$ 20 \mathrm{M}$, with $\$ 3 \mathrm{M}$ for equipment not now available in Bldg 332)

\begin{tabular}{|c|c|c|}
\hline $\begin{array}{l}\text { Foundry } \\
\text { Casting Line } \\
\text { Heat Treatment } \\
\text { Thermocycler } \\
\text { Work Box, Mold Coater } \\
\text { Annealing Furnace }\end{array}$ & $\begin{array}{l}\text { Machining } \\
\text { Moore T \& Box } \\
\text { CNC Mill \& Box } \\
\text { Lathe \& Box } \\
\text { Degreaser } \\
\text { LeBlond Lathe* } \\
\text { Monarch Lathe* }\end{array}$ & $\begin{array}{l}\text { Inspection } \\
\text { Sheffield, Rotary Contour } \\
\text { Surface Finish Profilometer } \\
\text { Radiography } \\
\text { Surface Plate Box } \\
\text { Density \& Weight } \\
\text { Surface Roughness* } \\
\text { Optic Comparator* }\end{array}$ \\
\hline$\frac{\text { Processing }}{\text { sopress }}$ & $\begin{array}{l}\text { Joining } \\
\text { Hot Laser Welder } \\
\text { Cold Laser Welder } \\
\text { Laser Power Supply } \\
\text { E Beam Weld \& Box } \\
\text { MIG/TIG \& Box }\end{array}$ & $\begin{array}{l}\text { Assembly } \\
\text { Work Box } \\
\text { Downdraft Table } \\
\text { Pumpdown/Backfill } \\
\text { Autoclave* } \\
\text { Conveyer* } \\
\text { Hood }\end{array}$ \\
\hline
\end{tabular}

Characterization $(\$ 9 \mathrm{M}$ with $\$ 1.6 \mathrm{M}$ for equipment not now available in Bldg 332)

Analytical Chem
Wet Chem Line
GasAnal(C,N,O,H)
E Spec\&Box
ICP Mass Spec*
DCP
Sample Prep*
Counting Equipment

$\begin{array}{ll}\text { Metallography } & \text { X Ray } \\ \text { Sample Prep Line } & \text { Diffraction } \\ \text { Metallographs etc } & \text { Flourescence } \\ & \text { Generators } \\ & \text { Boxes } \\ & \text { XRF* } \\ & \text { Colorad Camera* } \\ & \text { Fiberoptic Spec* }\end{array}$

Metallurgy ( $\$ 6 \mathrm{M}$ with $\$ 2.5 \mathrm{M}$ for equipment not now available in Bldg 332)

\begin{tabular}{l} 
Electron Optics \\
\hline TEM* \\
SEM \\
Auger* \\
Microprobe
\end{tabular}

Physical Met

Physical Met Box*

Dilatometry 
Enhanced Safety ( $\$ 10 \mathrm{M}$ with $\$ 1 \mathrm{M}$ for equipment not now available in Bldg 332)

Full up Fire Safety Furnace \& Box

Developmental Fire Safety Furnace \& Box

Mechanical Testing \& Box ( Two Instrons)/ (* one)

Snuttering R\&D

Arc Melting

Dry Train

High Temperature/High Vacuum Box

Thermal Analysis \& Dilatometer

Srecial Purpose Box*

General Purpose Box

Sample Prep Box

Mfg. and Process Development for Reconfiguration ( $\$ 63 \mathrm{M}$ with $\$ 46 \mathrm{M}$ for equipment not now available in Bldg 332)

Manufacturing

Prototype Die Casting*

Real Time Radiography*

Processing

Hydrochlorination/salt chlorination Actinide spectroscopy

Tilt pour furnace

Non destructive analysis

Material transfer boxes (2)

Casting development

Isotope Sepration

$\mathrm{Pu} /$ gas kinetics

Overhead conveyers (2)

Stationary furnaces (4):

DOR/ ER/MSE development

Hydride /dehydride

Calcining

Vacuum evap/Am separation

Processing(cont'd)

Disássembly*

Hydride/dehydride

plant prototype*

Decontamination*

Automated tilt pour prototype* Charge makeup/breakout*

Incot casting prototype*

In line storage*

$\mathrm{NDA}^{*}$

Evaporative Puriñication*

CEPOD pr,totype*

Aqueous teed prep*

Interglovebox transport*

Utility gloveboxes*

Calcination*

Salt Regeneration/Electrowinning Scrap sort*

Waste treatment*

Analytical chem sample prep*

Overhiead conveyers (2)* 
Special Project (already located at LANL)

E05 Pu gun

Small experiments

\section{Weaponization $(\$ 10)$}

Boxes for Live Pit assembly \& disassembly

Compatibility Testing \& Boxes

Hardened Engineerirg Test Building**

Intrinsic Radiation

Environmental Testing

** Please note that HETB is a specially designed facility for live pit assembly and disassembly study as well as intrinsic radiation.

It contains $8000 \mathrm{sq} \mathrm{ft}$. 

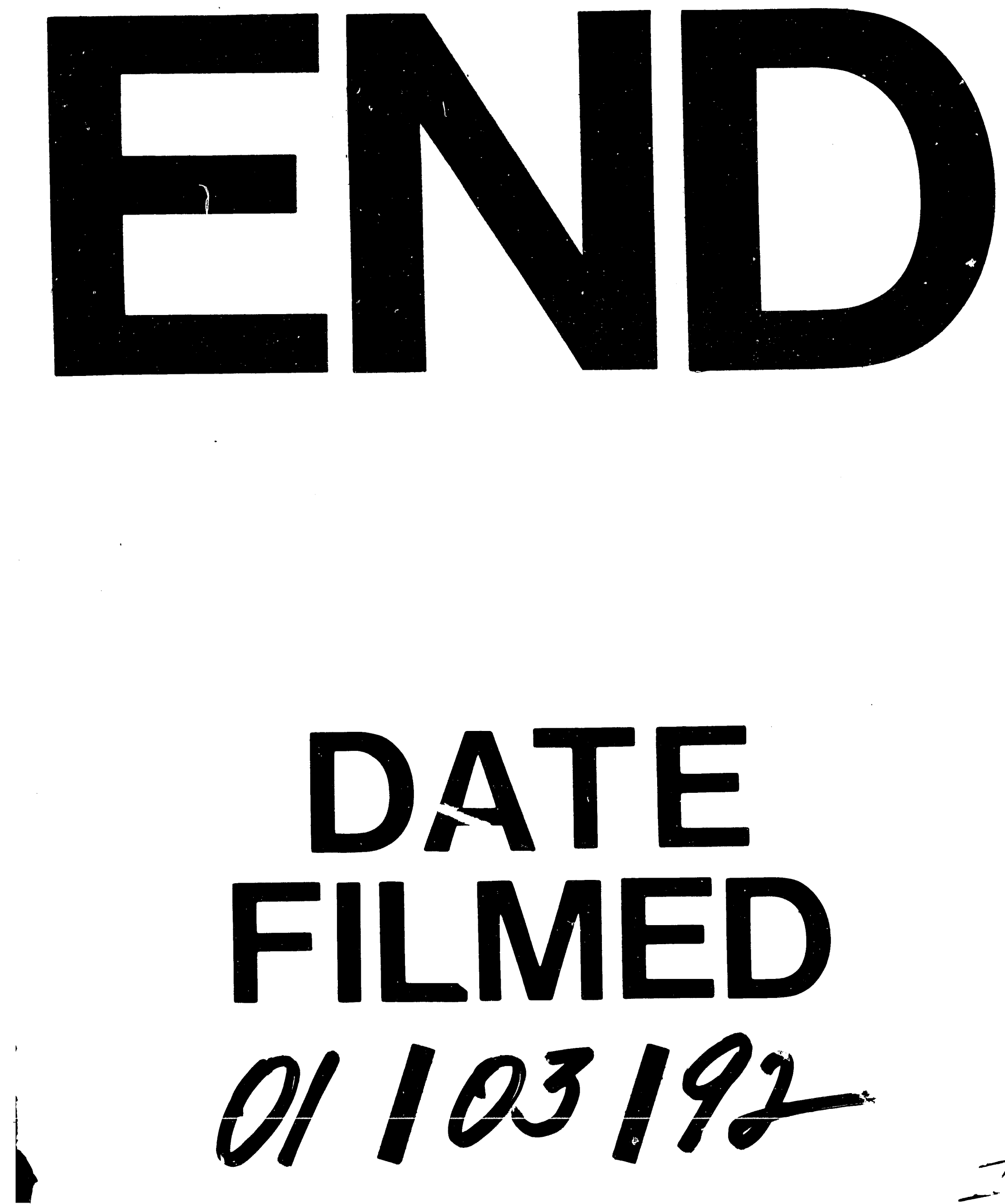
